\title{
Lao Tse y el Tao te Ching
}

\author{
Lao Tse and Tao te Ching
}

\author{
MARÍA TERESA ROMÁn LÓPEZ* \\ Universidad Nacional de educación a Distancia - UNED*
}

\begin{abstract}
RESUMEN
En este artículo describiremos algunos de los aspectos más reveladores de la obra y del pensamiento de Lao tse que, en cierta medida, pueden ayudarnos a entender algunas de las razones que justifican la gran influencia que el taoísmo ha tenido en el mundo oriental antiguo $y$, en particular, en el pensamiento de China.
\end{abstract}

\section{PALABRAS CLAVE}

Lao tse, Tao te ching, Zhuang zi, Confucio, taoísmo, Tao, wu wei, el Lao zi de Guodian, los Libros de Mawandgdui, las versiones tardías.

\begin{abstract}
In this article we will describe some of the most developing aspects in the book and of the thought of Lao tse that, in certain measure, they can help us to understand some of the reasons that justify the great influence that the Taoism has had in the old oriental world and, in particular, in the thought of China.
\end{abstract}

\section{KEYWORDS}

Lao tse, Tao te ching, Zhuang zi, Confucio, Taoism, Tao, wu wei, Lao zi of Guodian, Books of Mawandgdui, the late versions.

\section{INTRODUCCIÓN}

\author{
«Mis razones \\ harto fáciles son de comprender, \\ harto fáciles de ejercitar. \\ En el mundo nadie hay capaz de comprenderlas, \\ nadie capaz de ejercitarlas. \\ Las razones han de tener un origen \\ y los actos un señor. \\ Como (los hombres) no los conocen, \\ tampoco me conocen a mí. \\ Raros son los que me conocen, \\ de gran mérito los que me siguen»
}

Tao te ching LXX

* Departamento de Filosofía de la UNED. Paseo Senda del Rey, 7. 28040 Madrid. E-mail: mroman@fsof.uned.es 
En el período antiguo se crean y desarrollan las grandes corrientes filosóficoreligiosas que imperarán en todo el pensamiento chino: el confucianismo y el taoísmo ${ }^{1}$. Esto fue así tras una dilatada evolución, y desde el siglo $-\mathrm{V}$ al siglo -III, sólo fueron dos entre numerosas escuelas de pensamiento rivales. Durante ese tiempo, el número de escuelas era tan elevado que algunos estudiosos chinos se referían a ellas como las «cien escuelas». El gran historiador de la dinastía Xi Han (Han del Oeste) y autor del Shi ji (Registros Históricos), es el primero que hace una clasificación de las escuelas, a saber: la escuela de yin yang, la de los letrados o confucianistas, la moísta, la de los nombres, la de los legalistas y la taoísta.

En los años -340 a -240 surgen ligados a los nombres de Lao tse o Lao zi, Chuang tse o Zhuang $\mathrm{zi}^{2}$ y Lie $\mathrm{zi}^{3}$, unos tratados que constituyen el fundamento del denominado «taoísmo filosófico» ${ }^{4}$. Estos viejos tratados contienen sentencias de sabiduría práctica, dichos, parábolas, aforismos, anécdotas semihistóricas, e información sobre la existencia de una «escuela de higiene» en aquellos tiempos que habla de una serie de pautas enfocadas a prolongar la vida.

En este artículo describiremos algunos de los aspectos más reveladores de la obra y del pensamiento de Lao tse, que, en cierta medida, pueden ayudarnos a entender algunas de las razones que justifican la influencia profunda que el taoísmo ha tenido en el mundo oriental antiguo y, en particular, en el pensamiento de China. Como sucede con los textos sapienciales y sus supuestos autores, su interpretación no se agota en un solo sentido ni se puede plasmar en un único cuadro.

1 «Girando entre sí como círculos, a modo del yin y el yang, el taoísmo y el confucianismo representan los dos polos autóctonos del temperamento chino. Confucio representa lo clásico, Lao Tsê lo romántico. Confucio subraya la responsabilidad social, Lao Tsê ensalza la espontaneidad y la naturalidad. Confucio se concentra en lo humano, Lao Tsê en lo que lo trasciende. Como dicen los propios chinos, Confucio ronda entre la sociedad, Lao Tsê merodea por el más allá. Algo hay en la vida que nos conduce hacia una de estas dos direcciones y, sin duda, la civilización china sería más pobre si ninguna de las dos hubiese aparecido». H. Smith, Las religiones del mundo, Thassalià, Barcelona, 1995, p. 229.

2 «El Taoísmo debe su más completa y alta formulación a algunos sistematizadores, entre los que se distinguen Lao-tze y Chuang-tze; el primero está considerado erróneamente, como el fundador del sistema; el segundo vivió algunos siglos después que el maestro, y, sin temor de exageración, es el más profundo, sutil y ardiente apóstol de la fe taoísta, que en sus páginas, admirables por la expresividad artística y la originalidad del pensamiento, ha encontrado la más alta y completa sistematización. De uno y otro conocemos muy poco, como si el hado mismo no hubiera querido oponerse a aquel vivo deseo de olvido y a aquella modestia que animan la obra de los dos misteriosos filósofos. Cuando el nombre de ambos se hizo célebre, la leyenda se apoderó de ellos, sobre todo de Lao-tze, y se ingenió, en múltiples obras, para narrar eventos milagrosos y extrañas aventuras, queriendo de tal modo suplir la escasez de datos históricos». G. Tucci, Apología del taoísmo, Dédalo, Buenos Aires, 1976, pp. 8-9.

${ }^{3}$ Héroe de algunas anécdotas referidas por Zhuang zi, es posible que se tratara de un personaje imaginario. El tratado que lleva su nombre aglutina textos antiguos y recientes.

${ }^{4}$ Feng Youlan juzga necesaria y justificada la distinción entre el taoísmo filosófico (daojia), y el taoísmo religioso o «religión taoísta» (daojiao). Según éste investigador: «Sus enseñanzas no sólo son distintas: son hasta contradictorias. El taoísmo como filosofía enseña la doctrina de seguir a la naturaleza, mientras que el taoísmo como religión enseña la doctrina de actuar contra la naturaleza. Por ejemplo, según Lao Tse y Chuang Tse, la vida seguida por la muerte es el curso de la naturaleza, y el hombre debe seguir apaciblemente este curso natural. Pero la principal enseñanza de la religión taoísta es el principio y la técnica de cómo evitar la muerte, lo que es actuar expresamente contra la naturaleza». Fung Yu-Lan, Breve historia de la filosofía china, Fondo de Cultura Económica, México, 1987, pp. 26-27. 
Dada, pues, la imposibilidad de ofrecer una información completa y pormenorizada de la obra y del autor del Tao te ching («El Libro del Tao») y asumir una totalidad más allá de nuestras posibilidades, hemos convertido nuestra tarea en una fructífera aproximación.

\section{2. «EL ANCIANO MAESTRO»}

Al parecer, el taoísmo ${ }^{5}$ comenzó con Lao tse («Anciano Maestro»), un misterioso sabio atrapado en las inexorables redes de la leyenda, como la de que la madre de Lao tse, a los ochenta y un años, habría sido fecundada por un rayo de sol y que el «Anciano Maestro» estuvo en el útero materno durante cuarenta y dos años y, cuando nació, era ya un hombre sabio de cabellos blancos ${ }^{6}$. $\mathrm{Y}$, sin embargo, la historia de su vida, sea verdad o ficción, es tan real que sigue aun hoy formando parte de la cultura china. El problema relativo a la identidad del supuesto autor del Tao te ching aun no se ha resuelto satisfactoriamente.

Antes de que se excavaran las tumbas de Mawangdui y Guodian, los eruditos manejaban diversas teorías acerca de Lao tse ${ }^{7}$. Una primera hipótesis señala que Lao tse es Lao Dan; éste vivió a finales de la época Primavera y Otoño (-770 a -476) y fue coetáneo de Confucio y cronista durante un periodo de tiempo en la corte de Zhou. Esta opinión se apoya sobre todo en el testimonio de Sima Qian.

Asimismo encontramos a Lao Dan en el Lie zi y en el Zhuang zi, los grandes tratados del taoísmo filosófico. En esta última obra, Lao Dan es el personaje principal de diversos diálogos y anécdotas, entre los que sobresale un encuentro entre éste y Confucio:

${ }^{5}$ El término taoísmo sirve para nombrar dos manifestaciones distintas. En primer lugar, el taoísmo filosófico, con sus grandes representantes: Lao zi y Zhuang zi. En segundo lugar, el taoísmo religioso, con sus diversas escuelas que tienen como meta suprema la prolongación de la vida: «Únicamente los dos libros titulados Tao Tê Ching y Zhuang zi representan para nosotros el "taoísmo filosófico" que debía posteriormente, amalgamándose con diversas creencias, dar nacimiento al "taoísmo religioso" 》. M. Kaltenmark, La filosofía china, Morata, Madrid, 1982, p. 34.

6 «Es muy del agrado de los corazones creyentes hacer aparecer el nacimiento de un santo en circunstancias que se apartan del curso normal de las cosas. Con frecuencia se halla la idea de que el padre o los padres eran tan ancianos, que fue un milagro que pudieran tener todavía un hijo [...] La madre de Lao-Tse, a los 81 años, habría sido fecundada por un rayo de sol». H. von Glasenapp, El budismo una religión sin Dios, Barral, Barcelona, 1974, pp. 115-116.

7 Véase Lao tse, Tao te ching. Los Libros del Tao, Trotta, Madrid, 2006, pp. 22-29.

8 Sima Qian relata un encuentro entre Confucio y Lao tse. Según Mircea Eliade: «Este encuentro es ciertamente apócrifo, al igual que todas las restantes tradiciones consignadas por Sseu-ma Ts'ien. Pero expresa, con sencillez y humor, la incompatibilidad entre los dos grandes pensadores religiosos. Pues, como añade el historiador, «Lao tzu cultivaba el Tao y el Tö; según su doctrina hay que aplicarse a vivir oculta y anónimamente. Pero vivir al margen de la vida pública y despreciar los honores era justamente todo lo contrario del ideal del "hombre superior" propuesto por Confucio". Historia de las creencias y de las ideas religiosas, Cristiandad, vol. II, Madrid, 1978, p. 39. Se dice que Confucio se refirió al «Anciano maestro» en los siguiente términos: «"Las aves, lo sé, pueden volar;los peces, lo sé, pueden nadar, los animales, lo sé, pueden correr...; pero, por lo que se refiere al dragón, no sé cómo hace para elevarse sobre el viento y las nubes, hacia el cielo. He visto ahora a Laotsé. ¿No es éste como el dragón?". Laotsé le dio, al despedirse, consejos bien intencionados: El que habla se pierde fácilmente en dis- 
«A sus cincuenta y un años Confucio aún no había recibido la enseñanza del Tao. Viajó, pues, al sur, a Pei, para visitar a Lao Dan.

«Así que habéis venido — dijo Lao Dan-. He oído decir que sois un sabio del norte. ¿Estáis ya en posesión del Tao?»

—«Aún no - respondió Confucio.

— ¿Qué habéis hecho para encontrarlo?»—preguntó Lao zi.

— «Lo busqué durante cinco años estudiando las medidas y los números —dijo Confucio-; más no lo conseguí»

— «Y después, ¿cómo lo buscasteis?»

— «Durante doce años lo estuve buscando en el estudio del Yin y el Yang, mas tampoco lo conseguí».

«Así es —dijo Lao zi-. Si se pudiese ofrecer ofrenda del Tao, ningún súbdito dejara de ofrendárselo a su príncipe; si el Tao se pudiese presentar, ningún hijo dejara de presentárselo a sus padres; si el Tao se pudiese enseñar, nadie dejara de enseñárselo a sus hermanos; si el Tao se pudiese dar, nadie dejara de dárselo a sus hijos y nietos. Mas no se puede, y no hay razón, que como en tu interior no haya principio rector, el Tao se no ha de asentar en ti, no lo podrás ejercitar cuando no lo pruebes en el exterior. Cuando se atiene a los dictados de su comprensión interior y no se le acepta en el exterior, el sabio no se manifiesta; cuando se atiene a los dictados del exterior y no tiene dentro sí principio rector, el sabio no se oculta. El renombre es algo público, de lo que no se debe uno apropiar en exceso. La benevolencia y la justicia son el albergue de los antiguos soberanos, en el que sólo se puede parar una noche, y no permanecer largo tiempo; si haces porque te vean en él, menudearán los reproches hacia tu persona.

"Los hombres perfectos de la antigüedad tomaban el camino de la benevolencia y hacían alto en la justicia, por viajar hasta la liberadora Vacuidad. Alimentábanse frugalmente y se asentaban en huertos no arrendados. La plena libertad está en el no-actuar; siendo frugal, siempre se está satisfecho; al no arrendar, no se consume. A esto llamaban antiguamente «Viaje a la verdad».

"Quien considera su meta las riquezas, no cederá a otro sus rentas; quien considera su meta la gloria, no cederá a otro su fama; los ansiosos de poder, no consentirán en ceder a otro el mando. Tiemblan cuando lo tienen, se afligen cuando lo pierden. En su mente, empero, nada de esto ven con claridad: antes miran perseverar en su empeño. Es como si el Cielo los hubiera condenado. Agraviar y favorecer, tomar y dar, amonestar e instruir, perdonar la vida y condenar la muerte, tales son los ochos instrumentos para corregir a los hombres, de los que sólo puede usar aquel que debe acomodarse a las grandes mudanzas, sin que se lo es-

putas, el que oye sufre con facilidad equivocaciones motivadas por las palabras. Cuando se conocen estos dos peligros, no se puede errar el buen camino...». R. Wilhelm, Kungtse (Confucio), Revista de Occidente, Madrid, 1926, pp. 14-15. Este diálogo parece reflejar la rivalidad existente entre el confucianismo, orientado hacia las cosas de este mundo al que quiere mejorar y configurar, preocupándose de fortalecer el Estado y los estilos de gobierno, y el taoísmo, más preocupado por la causa primera del mundo y a buscar una "salida» más allá de él: «Observando más el aspecto metafísico del problema, la filosofía de Lao-Tse es una "receta de santidad", mientras que la de Confucio es una "fórmula de gobierno y de práctica social, para utilizar las felices palabras de Granet"». J.R. Rivière, El pensamiento fiIosófico de Asia, Gredos, Madrid, 1960, p. 303. 
torbe el deseo de las cosas. De ahí el dicho: «Sólo puede corregir a los demás el que antes se ha corregido a sí mismo». Si en tu mente no lo ves así, las puertas del Cielo no se abrirán»?.

Una segunda hipótesis señala que Lao tse es Taishi Dan, que vivió durante el periodo de los Reinos Combatientes (-441 a -221). Por su parte, Guo Moruo señala que el Lao zi es obra de Huan Yuan, un filósofo taoísta de la época de los Reinos combatientes. Otra opinión es la de Feng Youlan, quien afirma que el autor de la biblia taoísta es un tal Li Er, también de la época de los Reinos Combatientes. Igualmente, se ha barajado la idea de que el Tao te ching es el corolario de una prolongada compilación y elaboración en las que participó una escuela a lo largo de mucho tiempo. Éstas son algunas de las teorías que se manejaban a comienzos de los años noventa del pasado siglo hasta que se produjo el descubrimiento de Guodian. Aun hoy no faltan sinólogos que simpatizan con la idea de la inexistencia de Lao tse y la autenticidad del Tao te ching. En todo caso, la cuestión, de cualquier modo que se resuelva, tiene una importancia harto secundaria. Sobre la biografía de Lao tse, el Lao zi liezhuan del Shi ji afirma lo siguiente:

«Lao zi era natural de la aldea de Quren, en el municipio de Li, del distrito de $\mathrm{Ku}$, en el Estado de Chu [...] Fue cronista de la corte de Zhou. Confucio se dirigió a Zhou para preguntar a Lao zi acerca de los ritos. Lao zi le dijo: «Toda vuestra enseñanza no pasa de ser palabras dichas por hombres que hace mucho desaparecieron junto con sus huesos. Cuando un hombre virtuoso se acomoda a su tiempo marcha en carruaje, y cuando no, se mueve sin rumbo llevado por el viento. He oído decir que un buen comerciante guarda bien su mercancía aparentando no tener ninguna, y que el hombre virtuoso, dotado de grandes prendas, parece un estúpido. Suprimid vuestra arrogancia y vuestra ambición, vuestra obsequiosidad y vuestra lascivia; todo ello no favorece en nada a vuestra persona. Esto es todo lo que tengo que deciros». Confucio se alejó y dijo a sus discípulos: «Sé que un pájaro vuela, que un pez nada, que un animal anda; para lo que anda, puedo hacer trampas; para lo que nada, puedo hacer sedales; para lo que vuela, puedo hacer arcos y flechas. En cuanto al dragón, sin embargo, escapa a mi inteligencia de qué manera se eleva hasta el cielo montado en el viento y en las nubes. Después de haberlo visto hoy, pienso si Lao zi no será como un dragón». Lao zi cultivó el Tao y su virtud; basó su doctrina en el vivir ignorado, sin renombre alguno. Vivió largo tiempo en Zhou; mas al ver la decadencia de este Estado se marchó. Cuando llegó al Pao (Guan), el encargado de su defensa (Guan Yin) le dijo gozoso: «Ya que vais a abandonar el mundo, escribid un libro para mi provecho". Lao zi entonces escribió una obra compuesta de dos libros (pian) en la que habla, utilizando más de cinco mil caracteres, del sentido del Tao y de su virtud (Te); luego se alejó. Nadie sabe dónde terminó su viaje ${ }^{10}$.

Lo demás es misterio, pero este misterio pone al descubierto la personalidad del «Anciano maestro» mejor que una suma de detalles. Los hombres interiores carecen de biografía y la penumbra es el mejor espacio para este atractivo e influyente personaje del mundo antiguo. En el capítulo XX del Tao te ching leemos:

9 I. Preciado (ed.), Zhuang zi «Maestro Chuang Tsé», Kairós, Barcelona, 1996, pp. 154-155.

10 Lao Tse, Tao te ching. Los Libros del Tao, ed.cit., p. 23. 


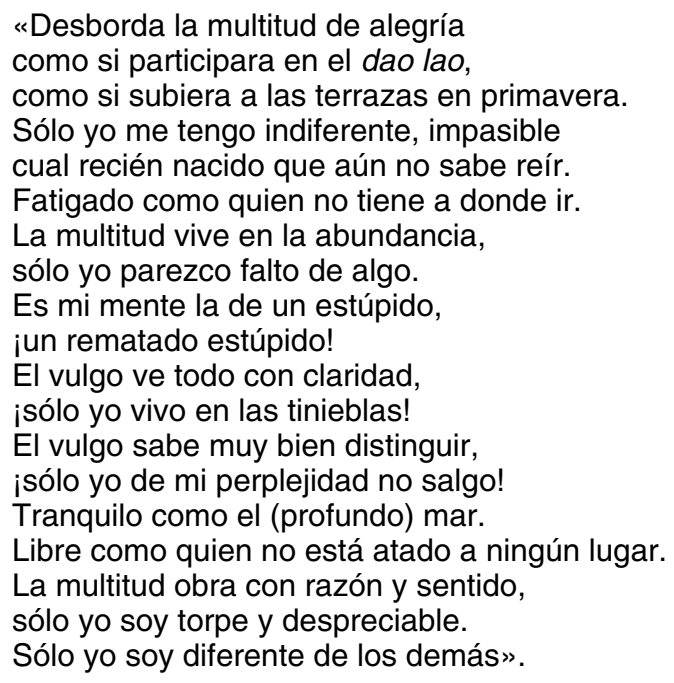

\section{EL TAO TE CHING}

Más que el nombre de un personaje histórico, la crítica europea ve en Lao tse el título de una obra, llamada también Tao te ching (Daodejing), «El libro del Tao» y que en castellano podría traducirse aproximadamente por "Libro de la Vía y de su Virtud».

Existen tres versiones principales del Lao zi: el Lao zi de Guodian, los Libros de Mawandgdui y las versiones tardías, las más conocidas y divulgadas hasta la fecha. La versión más antigua del Lao zi de Guodian, se atribuye a Lao Dan, mientras que los Libros de Mawandgdui y las versiones tardías son obra de Taishi Dan, dos de los tres personajes relacionados con la figura de Lao tse.

En 1973, al excavar la tumba Han n. 3 de Mawangdui, se halló un grupo de antiguos libros de seda y, entre ellos, dos copias del Lao zi. La primera copia, fechada entre -206 y -195 , y la segunda, entre -194 y -180 . Veinte años después se descubrió una tumba en la aldea de Guodian, en el centro de China, y en su interior se halló una abundante cantidad de textos escritos sobre tablillas de bambú entre los cuales figuraba una copia, la más antigua de las conocidas hasta este momento, del Tao te ching, compuesta de setenta y una tablillas agrupadas en tres haces ${ }^{11}$.

Muchos investigadores, tras comparar detenidamente las tres versiones, han llegado a la conclusión de que el Lao zi de Guodian, por una parte, y el Lao zi Mawangdui y las versiones posteriores, por otra, pertenecen a diferentes tradiciones, transmisiones o subescuelas. Nos hallaríamos, por consiguiente, ante al menos dos diferentes líneas de transmisión de esta fuente de la sabiduría universal.

11 Véase ibíd., pp. 19-22. 
No cabe duda de que el El Tao te ching es una de las obras más profundas y fascinantes de la filosofía universal y una fuente de sabiduría inagotable. En este tratado sapiencial hallamos un escenario con ideas bastante alejadas de nuestros parámetros mentales occidentales ${ }^{12}$, a saber:

«Elimínese la sabiduría, rechácese la inteligencia, y las gentes obtendrán beneficios cien veces mayores. Elimínese la benevolencia, rechácese la rectitud, y las gentes retornarán a la piedad filial y al amor. Elimínese la industria, rechácese el interés y ya no habrá bandidos ni ladrones. Estas tres (razones), tomadas como normas (de gobierno), no bastan y por ello es menester hacerles saber a qué atenerse: ser modestos por fuera y conservar la simplicidad interior, ser menos interesados (y) con escasos deseos» (XIX).

«Conocer a los demás, inteligencia. Conocerse a sí mismo, clarividencia. Vencer a los demás, fortaleza. Vencerse a sí mismo, poderío. Saber contentarse, riqueza. Esforzarse, voluntad» (XXXIII).

«El más grave de los males, los muchos deseos; el más doloroso de los defectos, la ambición; la mayor de las desgracias, no saberse nunca contento: El (verdadero) contento es saberse contentarse; ése es el contento perdurable» (XLVI).

«Un buen caudillo militar no usa de las armas, un buen guerrero no se deja llevar de la ira, quien saber vencer a su enemigo no entabla con él combate, quien sabe usar a los hombres se acomoda debajo de ellos. A eso llaman virtud de no-luchar, a eso llaman poder de usar a los hombres, a eso llaman ley suprema de la armonía con el Cielo» (LXVIII).

«Las palabras verdaderas no son gratas, las palabras gratas no son verdaderas. El hombre bueno no se justifica, quien se justifica no es bueno. El saber no es erudición, el erudito nada sabe. El sabio no acumula, obra enteramente para los otros y posee cada vez más, lo da todo a los demás y tiene más cada veZ» (LXXXI).

En realidad, los mensajes que encontramos en el Tao te ching no son rebuscados y sus ideas están repetidas en forma epigramática una y otra vez y son claras, profundas y prácticas. Brevemente los contenidos son: «El ritmo de la vida, la unidad de todos los fenómenos humanos y mundiales, la importancia de mantener la simplicidad original de la naturaleza humana, el peligro de excederse en el gobierno y la interferencia con la vida simple del pueblo, la doctrina wu wei o «inacción», que está mejor interpretada como «no interferencia» [...] la influencia creciente del espíritu, las lecciones de humildad, quietud y calma, y lo tonto de la fuerza, del orgullo y del propio consentimiento ${ }^{13}$.

12 «El mensaje del Laozi empieza, pues, con una paradoja de choque que fue inmediatamente captada por su primer público [...] La paradoja consiste en pensar al contrario de lo habitual: preferir lo débil a lo fuerte, la no-acción a la acción, lo femenino a lo masculino, lo inferior a lo superior, la ignorancia al conocimiento, etc. [...] Ahora bien, la paradoja más radical consiste sin duda en decir que la nada tiene más valor que algo, que el vacío vale más que la plenitud, que el "no haber [...] vence al haber" [...] La paradoja lleva a su punto álgido: la ausencia tiene más presencia que lo que está aquí, el vacío tiene una eficacia que la plenitud no tiene [...] La paradoja que contradice los hábitos intelectuales los valores convencionales tiene por objeto demostrar que enunciar una cosa es enunciar su contraria. Las distinciones y las oposiciones que hacemos por costumbre o por convención no tienen, en sí, ningún valor». A. Cheng, Historia del pensamiento chino, Bellaterra, Barcelona, 2002, pp. 168-169.

${ }_{13}$ Lin Yutang, Sabiduría china, Biblioteca Nueva, Buenos Aires, 1959, pp. 21-22. 
En su estudio preliminar a Lao tse, Carmelo Elorduy señala lo siguiente sobre el Libro del Tao: «El Tao-Te-Ching por su sencillez, por su profundidad humana y su primitivismo, es camino abierto y llano para toda inteligencia suficientemente desarrollada y naturalmente capaz. Es camino cuya trayectoria se puede recorrer en pleno campo a la luz del sol. Sus conceptos básicos están limpios de toda maleza irracional mística. Por estar inspirado en la capacidad progresiva de las fuerzas naturales, está en constancia con los postulados científicos. Es una metafísica dialécticamente no desarrollada, pero fecunda en visiones conceptuales adecuadas para captar las manifestaciones primordiales e intemporales del ser. El pensamiento esencialmente humanista del Tao Te Ching se presta tanto al conocimiento de las fases prehistóricas del hombre sobre la tierra como para fijar las leyes fundamentales de sus destinos históricos y eternos ${ }^{14}$.

\section{LA DOCTRINA DE LAO TSE}

La doctrina de Lao tse ha sufrido tantos tratamientos que su análisis resulta poco menos que imposible. Todo el pensamiento taoísta en general, y el de Lao tse en especial, se mueve alrededor del concepto del Tao. El sentido de la palabra Tao desborda por doquier las traducciones posibles. Lao tse la empleaba a modo de aproximación para designar el principio de todas las cosas, la propia Realidad suprema. Para von Glasenapp, el Tao de Lao tse es «el principio eterno de todas las cosas, una fuerza que sostiene cuanto existe; es al mismo tiempo la ley que actúa en el mundo sin hablar ni obrar, y que traza la línea de lo justo. Es asimismo el Único eterno, el más excelso principio del mundo natural y moral» ${ }^{15}$. En realidad, el Tao es lo Absoluto impersonal, la fuente de todas las cualidades. En el Tao te ching (XXV) leemos:
«Hay una cosa confusamente formada anterior al Cielo y a la Tierra.
¡Silenciosa, ilimitada!
De nada depende y su sufre mudanza, gira y retorna sin descanso;
puede ser tenida por madre del mundo.
Su nombre desconozco, la denominan Tao».

En el capítulo catorce del Lao zi hallamos algunos pronunciamientos en relación con el misterioso Tao:

«Lo miras y no lo ves,

Su nombre es yi.

Lo escuchas y no lo oyes,

su nombre es $x i$.

${ }_{14}$ C. Elorduy (ed.), Lao-Tse. La Gnosis taoísta del Tao Te Ching, Oña, Burgos, 1961, p. X.

15 Cit. en T. van Baaren, Las religiones de Asia, Plaza y Janés, Barcelona, 1967, p. 201. 


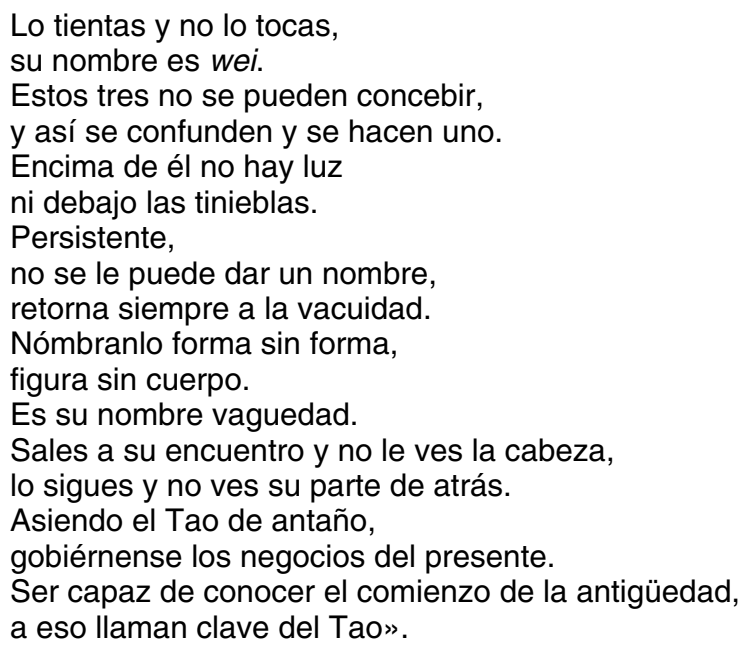

El Taoísmo emplea el término Tao con la significación de la totalidad de lo existente, semejante a lo que algunos eruditos occidentales han denominado «lo absoluto". El Tao es la materia prima de la que está constituido todo. Simple, informe, carente de deseos y afanes. Es anterior al Cielo y la Tierra. En el curso de la generación de cosas e instituciones, cuanto más se aleja el individuo de este estado originario, menos bueno y menos contento. Según el Lao zi (IV):

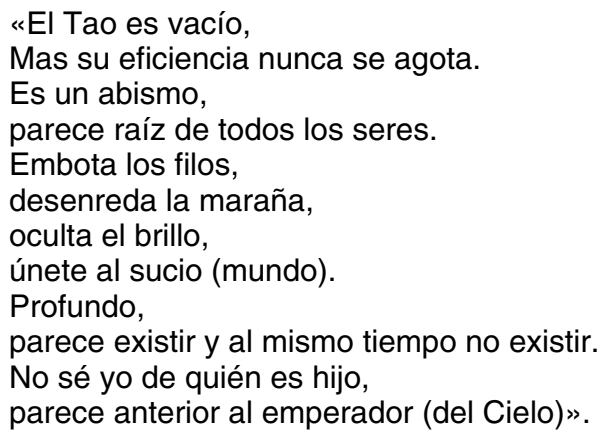

El Tao es la gran unidad, la unidad única en la que se trascienden todos los contrarios, la ausencia de dualidad. En el Zhuang zi leemos:

«No hay nada que no sea esto; no hay nada que no sea eso. Lo que no puede ser visto por esto (la otra persona) puede ser conocido por mí. Es por eso que digo esto emana de eso; eso también deriva de esto. Ésta es la teoría de la interdependencia de esto y eso (relatividad de los patrones).

No obstante, la vida surge de la muerte, y viceversa. Las posibilidades surgen de las imposibilidades y viceversa. Siendo éste el caso, el sabio verdadero rechaza todas las distinciones y se refugia en el Cielo (Naturaleza). Porque uno puede 
basarlo en esto, aunque esto es también eso y eso también esto. Esto también tiene su bien y su mal, y eso también tiene su mal y su bien. ¿Existe entonces realmente una distinción entre esto y eso? Cuando esto (subjetivo) y eso (objetivo) están sin sus correlativos, ése es el verdadero «eje del Tao». Y cuando ese Eje pasa por el centro donde convergen todos los Infinitos, las afirmaciones y las negaciones se mezclan por igual en Uno infinito ${ }^{16}$.

El Tao, el principio primordial, se confunde en algunas ocasiones con el vacío: «El Tao es vacío» (IV); «Treinta radios convergen en el cubo de una rueda, y merced a su vacío el carro cumple su misión. Modelando la arcilla se hacen las vasijas, y merced a su vacío las vasijas cumplen su misión. Horádanse los muros con puertas y ventanas al levantar la casa, y merced a su vacío la casa cumple su misión. $\mathrm{Y}$ así del ser dependen el uso y del no-ser que cumpla su misión» (XI); «La gran plenitud parece vacía» (XLV).

En algunos pasajes del Tao te ching, el Tao aparece identificado con la nada, con el no-ser: «El no-ser es principio del Cielo y de la Tierra; el ser, de los infinitos seres es madre. Por eso con el permanente no ser se contempla la esencia escondida (del Tao); con el permanente ser se contemplan meros indicios (del Tao). Estos dos (no-ser y ser) tienen el mismo origen aunque diferentes nombres» (I); «Nómbranlo forma sin forma, figura sin cuerpo» (XIV); «Los diez mil seres del mundo nacen del ser; el ser nace del no-ser» $(\mathrm{XL})$.

El Tao es como una fuerza que evoluciona en dos fases, el yin y el yang: «En las raíces mismas del pensamiento y el sentimiento chinos reposa el principio de polaridad, que no debe confundirse con los conceptos de oposición o conflicto. En las metáforas empleadas por otras culturas, la luz está en lucha con la oscuridad, la vida con la muerte, lo bueno con lo malo, lo positivo con lo negativo; así, a lo largo y a lo ancho del mundo florece un idealismo que pretende cultivar el primero y verse libre del último. Para el modo de pensar tradicional chino, esto resulta tan incomprensible como la existencia de una corriente eléctrica sin sus polos positivo y negativo, puesto que el concepto de polaridad se basa en el principio de que $+y-$, norte y sur, son aspectos diferentes de uno y el mismo sistema, y la desaparición de uno de ellos significaría la desaparición del sistema»17.

El Tao lo crea todo sin salir de su eterna inacción, y él permanece mientras que todo lo que ha creado crece y envejece, volviendo a la nada en ciclos perennes de un imperecedero devenir. Mas sólo los que conocen el Tao pueden perdurar:

«Los infinitos seres se desarrollan vigorosamente, y yo contemplo el (constante) retornar. Innumerable es la variedad de los seres, (mas) todos y cada retornan a su raíz.

Retornar a la raíz se llama "quietud";

${ }^{16}$ Lin Yutang, ob. cit., pp. 72-73.

17 A. Watts, El camino del Tao, Kairós, Barcelona, 1995, p. 55. 
quietud se llama "retornar a la propia naturaleza";

retornar a la propia naturaleza se llama «lo permanente";

conocer lo permanente se llama "clarividencia";

si no conoces lo permanente,

en tu ciego obrar hallarás la desgracia.

Sólo conociendo lo permanente, es posible abarcarlo todo;

sólo abarcándolo todo, se puede se ecuánime;

sólo siendo ecuánime, se puede ser universal;

sólo siendo universal, se puede alcanzar la unión con el Cielo;

sólo unido al Cielo, se puede alcanzar la unión con el Tao;

sólo hecho uno con el Tao, se puede perdurar:

hasta el final de tus días libre te verás de peligro» (Lao zi, XVI).

En el aspecto práctico y social, el taoísmo incluye el principio del «dejar hacer»: (wu wei): «El Tao permanente no actúa, mas nada hay que deje de hacer» (XXXVII); «Actúa sin actuar, ocúpate en no ocuparte en nada, saborea lo que no tiene sabor» (LXIII); «lo más débil del mundo, cabalga sobre lo más fuerte que en el mundo hay. El no-ser penetra donde no existe el menor resquicio. De ahí conozco yo el provecho del no-actuar. La enseñanza sin palabras, el provecho del no-actuar, pocas cosas en el mundo se les puede comparar» (XLII).

¿Qué significa wu wei? Se trata de no intervenir en el curso natural de las cosas; no hacer nada que no sea espontáneo y natural (es decir, exento de designio y no deliberado); no esforzarse de ninguna manera; ausencia de toda actividad volitiva, intencional o forzada. El Lao zi (XLVIII) describe la actitud de «no actuar» así:

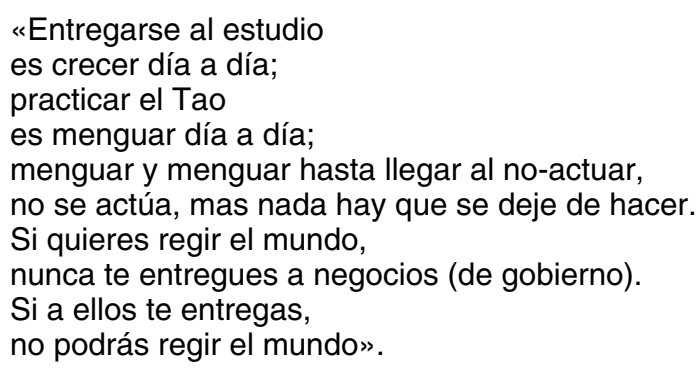

El wu wei consiste en un actuar libre de toda predeterminación y apetencia:

«Sin salir de tu propia casa,

puedes conocer el mundo.

Sin mirar por la ventana,

puedes conocer el Tao del cielo.

Cuanto más lejos vayas,

menor será tu saber.

Por eso el sabio conoce sin viajar,

distingue sin mirar,

realiza su obra sin actuar» (XLVII). 
Cualquier intervención por nuestra parte está destinada al fracaso:

«El que actúa, fracasa,

el que aferra algo lo pierde.

Por eso el sabio no actúa,

y de ese modo no fracasa,

nada aferra

y de ese modo nada pierde» (LXIV).

La actitud de «hacer nada» alcanza al modo de actuar del rey. Gracias a esta actitud puede el gobernante tener influencia y ejercer la autoridad.

«El Tao permanente, leño sin nombre

que, aunque fino, nadie en el mundo es capaz de avasallar;

si señores y monarcas lo pudieran conservar,

sometiéranseles de buen grado los infinitos seres.

Cuando el Cielo y la Tierra estaban unidos

se desprendió dulce rocío.

Como entre las gentes daba órdenes

se tenían por iguales.

Empezaron las jerarquías y con ellas los nombres (títulos),

habiendo aparecido los nombres,

habrá que saber detenerse;

sabiendo detenerse se podrá excusar todo daño» (XXXII). 